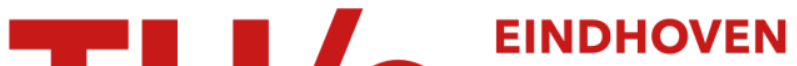 UNIVERSITY OF TECHNOLOGY
}

\section{Locally measured microstructural parameters are better associated with vertebral strength than whole bone density}

\section{Citation for published version (APA):}

Hazrati Marangalou, J., Eckstein, F., Kuhn, V., Ito, K., Cataldi, M., Taddei, F., \& Rietbergen, van, B. (2014). Locally measured microstructural parameters are better associated with vertebral strength than whole bone density. Osteoporosis International, 25(4), 1285-1296. https://doi.org/10.1007/s00198-013-2591-3

DOI:

10.1007/s00198-013-2591-3

Document status and date:

Published: 01/01/2014

\section{Document Version:}

Accepted manuscript including changes made at the peer-review stage

\section{Please check the document version of this publication:}

- A submitted manuscript is the version of the article upon submission and before peer-review. There can be important differences between the submitted version and the official published version of record. People interested in the research are advised to contact the author for the final version of the publication, or visit the $\mathrm{DOI}$ to the publisher's website.

- The final author version and the galley proof are versions of the publication after peer review.

- The final published version features the final layout of the paper including the volume, issue and page numbers.

Link to publication

\section{General rights}

Copyright and moral rights for the publications made accessible in the public portal are retained by the authors and/or other copyright owners and it is a condition of accessing publications that users recognise and abide by the legal requirements associated with these rights.

- Users may download and print one copy of any publication from the public portal for the purpose of private study or research.

- You may not further distribute the material or use it for any profit-making activity or commercial gain

- You may freely distribute the URL identifying the publication in the public portal.

If the publication is distributed under the terms of Article 25fa of the Dutch Copyright Act, indicated by the "Taverne" license above, please follow below link for the End User Agreement:

www.tue.nl/taverne

Take down policy

If you believe that this document breaches copyright please contact us at:

openaccess@tue.nl

providing details and we will investigate your claim. 


\section{Locally measured microstructural}

parameters are better associated with vertebral strength than whole bone density

\section{J. Hazrati Marangalou, F. Eckstein, V. Kuhn, K. Ito, M. Cataldi, F. Taddei \& B. van Rietbergen}

\section{Osteoporosis International}

With other metabolic bone diseases

ISSN 0937-941X

Volume 25

Number 4

Osteoporos Int (2014) 25:1285-1296

DOI 10.1007/s00198-013-2591-3

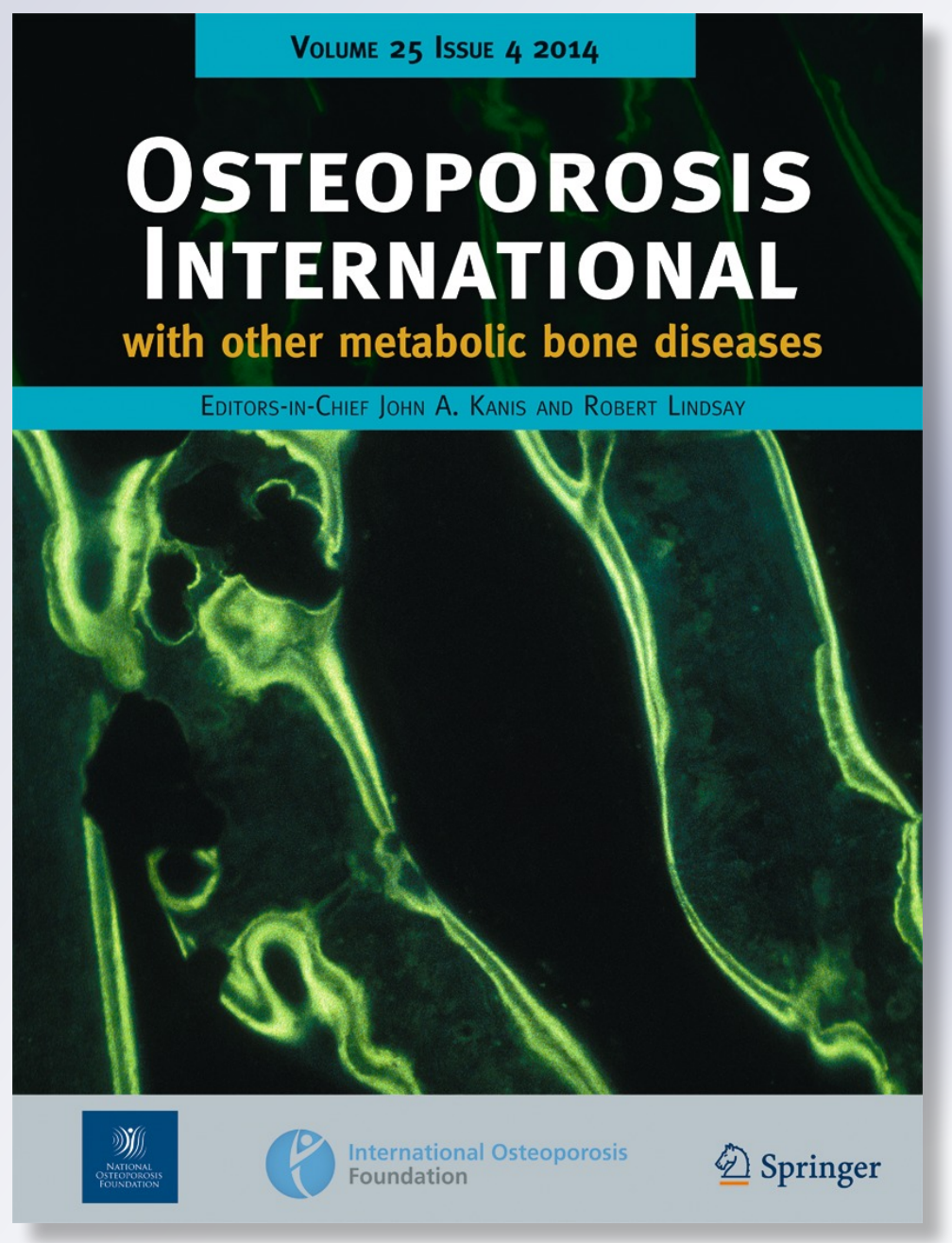

包 Springer 
Your article is protected by copyright and all rights are held exclusively by International Osteoporosis Foundation and National Osteoporosis Foundation. This e-offprint is for personal use only and shall not be selfarchived in electronic repositories. If you wish to self-archive your article, please use the accepted manuscript version for posting on your own website. You may further deposit the accepted manuscript version in any repository, provided it is only made publicly available 12 months after official publication or later and provided acknowledgement is given to the original source of publication and a link is inserted to the published article on Springer's website. The link must be accompanied by the following text: "The final publication is available at link.springer.com". 


\title{
Locally measured microstructural parameters are better associated with vertebral strength than whole bone density
}

\author{
J. Hazrati Marangalou • F. Eckstein • V. Kuhn • K. Ito • \\ M. Cataldi • F. Taddei $\cdot$ B. van Rietbergen
}

Received: 8 April 2013 / Accepted: 25 November 2013 /Published online: 4 December 2013

(C) International Osteoporosis Foundation and National Osteoporosis Foundation 2013

\begin{abstract}
Summary Whole vertebrae areal and volumetric bone mineral density (BMD) measurements are not ideal predictors of vertebral fractures. We introduce a technique which enables quantification of bone microstructural parameters at precisely defined anatomical locations. Results show that local assessment of bone volume fraction at the optimal location can substantially improve the prediction of vertebral strength.

Introduction Whole vertebrae areal and volumetric BMD measurements are not ideal predictors of vertebral osteoporotic fractures. Recent studies have shown that sampling bone microstructural parameters in smaller regions may permit better predictions. In such studies, however, the sampling location is described only in general anatomical terms. Here, we introduce a technique that enables the quantification of bone volume fraction and microstructural parameters at precisely defined anatomical locations. Specific goals of this
\end{abstract}

Electronic supplementary material The online version of this article (doi:10.1007/s00198-013-2591-3) contains supplementary material, which is available to authorized users.

J. Hazrati Marangalou $\cdot$ K. Ito $\cdot$ B. van Rietbergen

Orthopaedic Biomechanics, Department of Biomedical Engineering,

Eindhoven University of Technology, Eindhoven, The Netherlands

F. Eckstein

Institute of Anatomy and Musculoskeletal Research, Paracelsus

Private Medical University, Salzburg, Austria

V. Kuhn

Medizinische Universität Innsbruck, Innsbruck, Austria

M. Cataldi $\cdot$ F. Taddei

Laboratorio di Tecnologia Medica, Istituti Ortopedici Rizzoli,

Bologna, Italy

B. van Rietbergen $(\bowtie)$

Department of Biomedical Engineering, Eindhoven University of

Technology, PO Box 513, GEM-Z 4.118, 5600 MB Eindhoven,

The Netherlands

e-mail: B.v.Rietbergen@tue.nl study were to investigate at what anatomical location within the vertebrae local bone volume fraction best predicts vertebral-body strength, whether this prediction can be improved by adding microstructural parameters and to explore if this approach could better predict vertebral-body strength than whole bone volume fraction and finite element (FE) analyses. Methods Eighteen T12 vertebrae were scanned in a microcomputed tomography (CT) system and FE meshes were made using a mesh-morphing tool. For each element, bone microstructural parameters were measured and correlated with vertebral compressive strength as measured experimentally. Whole bone volume fraction and FE-predicted vertebral strength were also compared to the experimental measurements.

Results A significant association between local bone volume fraction measured at a specific central region and vertebralbody strength was found that could explain up to $90 \%$ of the variation. When including all microstructural parameters in the regression, the predictive value of local measurements could be increased to $98 \%$. Whole bone volume fraction could explain only $64 \%$ and FE analyses $76 \%$ of the variation in bone strength.

Conclusions A local assessment of volume fraction at the optimal location can substantially improve the prediction of bone strength. Local assessment of other microstructural parameters may further improve this prediction but is not clinically feasible using current technology.

Keywords Bone microstructure - Bone mineral density · Finite element analysis · Iso-anatomic mesh · Vertebral strength

\section{Introduction}

Osteoporosis is characterized by low bone mass and microarchitectural deterioration of bone tissue and represents a major public health problem due to the high prevalence and 
complications associated with fragility fractures [1-3]. It has been demonstrated that the clinical diagnostic standard approach based on site-specific BMD measurements using dualenergy X-ray absorptiometry (DXA) is not a satisfactory predictor of vertebral fractures $[4,5]$, and in general more than $50 \%$ of the osteoporotic fractures occur in patients with a DXAT-scores that do not meet the diagnostic criterion $(\leq-2.5$ SD) $[6,7]$. It has been stated that this poor performance could be related to the fact that DXA provides an areal density measure, and that it does not provide any information about the bone microarchitecture [5, 8-10]. Three-dimensional imaging techniques, such as $\mathrm{CT}$, enable the measurement of the volumetric density and, more recently, even some microstructural features of vertebrae in vivo [11-14]. Several studies have demonstrated, however, that the predictive value of quantitative computed tomography (QCT)-derived volumetric density for vertebral fractures generally is not much better than that of areal measures of density $[15,16]$, and the same has been shown in experimental studies on vertebral strength $[8,17]$.

Such volumetric density measures generally comprise the whole vertebrae. It has been proposed that assessment of the weakest parts of the cancellous bone may lead to better prediction of fracture risk [18]. Indeed, earlier studies demonstrated that sampling bone density and microstructural parameters in smaller regions can provide better predictions of vertebral strength [19-22]. The number of samples analyzed per vertebrae, however, was usually rather limited and, depending on the techniques used (experimental, computational), dictated by minimum size requirements for meaningful analysis of a bone sample. Further, the location of the samples was usually described only in terms of the anatomical planes, which makes it difficult to reproduce the exact anatomical location of the specimen, in particular for small samples. It is also unclear how sensitive the results are for small deviations from the sampling location. Although such studies could give general guidelines about the importance of different vertebral regions to predict vertebral strength, the results of these studies are hard to compare due to differences in experimental design, parameters investigated, techniques used, and sampling locations. However, the fact that most of these studies demonstrated that predictions can be improved by focusing the analysis on a specific region, begs the question if results can be further improved by finding an optimal location and size of the sampling region and if so, how these findings can be potentially translated to the clinic.

In order to answer that question, we hereby introduce a computational technique that enables the quantification of bone volume fraction and microstructural parameters at any precisely defined anatomical location in the bone. The approach relies on a combination of two essential tools as follows: The first is a morphing tool that can morph a 3D finite element (FE) mesh template to a CT-image of a bone after identification of a limited number of anatomical landmarks. After morphing, each element is positioned at a welldefined anatomical location in the bone. The second is a tool to measure bone volume fraction and microstructural parameters at the location of each element, hence at each anatomical location. The combined approach thus makes it possible to directly compare bone volume fraction and microstructure between bones at any given location. By correlating local values measured at a specific anatomical position for a large number of bones with whole bone strength, it then becomes possible to find which anatomical location best predicts whole vertebral-body strength. Since any particular anatomical location can be easily identified with the help of the mesh template and morphing tool, also for bone in vivo, such an approach could be used to improve bone strength predictions in patients, particularly in clinical studies.

In the present study, we explore this approach for thoracic (T12) vertebrae. The specific goals of the study were (a) to investigate at what anatomical location within the vertebrae local bone volume fraction best predicts whole vertebral-body strength, (b) to study whether the prediction can be further improved by measuring microstructural parameters, and (c) to explore if this approach could better predict bone strength than whole bone volume fraction and non-linear FE analysis.

\section{Material and methods}

\section{Material}

Eighteen vertebral segments comprising T11-L1 were obtained from an earlier study [23]. The donors were free of bone disease other than osteoporosis, as determined by histopathological examination of pelvic bone samples, and the vertebrae had no metastatic or other apparent disorder on radiography; they were stored in buffered formalin solution. Mean age was 78.0 \pm 8.07 years (range 64-92 years); ten donors were female and eight donors were male. The donors had dedicated their body by testament to the Institute of Anatomy in Munich during life for the purpose of teaching and research.

Imaging and mechanical testing

The central T12 vertebrae of each segment was scanned in a micro-computed tomography system (microCT 80, Scanco Medical AG, Brüttisellen, Switzerland) at a nominal isotropic resolution of $37 \mu \mathrm{m}$ using a $2,048 \times 2,048$ in plane image matrix. The scanner energy was $70 \mathrm{kV}(114 \mu \mathrm{A})$. Images were filtered using a modest Gauss filter (sigma $=0.6$, support $=1$ voxels) and segmented using a global threshold of $11 \%$ of the maximum gray value. Compartments of cortical and cancellous bone were identified using masks. A first mask comprising the whole vertebrae was made based on the periosteal 
contour. In order to separate the thin cortical shell, original images were filtered using a strong Gauss filter (sigma $=5$, support $=5$ voxels) and segmented using a threshold of $15 \%$ of the maximum gray value, leaving only the cortical bone. This image was used to identify the cortical shell in the original mask. In addition, the most periosteal 1-mm region of the original mask was identified as part of the cortical compartment. The remainder of the mask was then considered the cancellous compartment.

After imaging, the vertebral segments were tested to failure in an axial compressive loading configuration as a functional spinal unit (T11 to L1) with intact ligaments and intervertebral discs, but without posterior elements, using an uniaxial material testing machine (Zwick 1445, Ulm, Germany) and a $10 \mathrm{kN}$ load cell. The strength was determined at a rate of $6.5 \mathrm{~mm} / \mathrm{s}$ by identifying the first peak that is followed by a drop of $>10 \%$ from the load-displacement curve. To ensure fracture, the segments were compressed to $25 \%$ of their original height $[8,17,23]$.

\section{Creation of vertebrae meshes}

A mesh template for T12 vertebrae was created based on a mesh convergence study. The mesh template contained 51,119 tetrahedron second-order elements with a typical size of $1 \mathrm{~mm}$. To morph this template to a CT scan of a vertebra, a total of 22 specific anatomical landmarks at the bone periosteal surface were identified. To do so, a triangularized description of the periosteal surface of each vertebra was created from the $\mathrm{CT}$ scan using a marching cubes algorithm and converted to STL format (IPL V5.16, Scanco Medical AG). Using a dedicated morphing tool (Ansys, Inc., USA), the anatomical landmarks then were identified at the bone surface based on which the mesh template was automatically morphed to the CT scan. Using this procedure, it was ensured that each element of the mesh template corresponded to a specific anatomical location in all samples [24].

Bone volume fraction and microstructural analysis

Using an algorithm developed in-house, it was determined what fraction of the volume of each element in the mesh template was in the cancellous compartment and what fraction in the cortical compartment. If the element was at least partly in the cancellous bone compartment, a spherical region with a diameter of $4 \mathrm{~mm}$ was defined around the element centroid, for which the volume fraction and microstructural parameters were determined. The rationale for measuring microstructural parameters in a 4-mm sphere around the element was that, in order to define valid continuum level properties, measurements over a length scale on the order of $4 \mathrm{~mm}$ are required [25]. Microstructural analyses for the part of this spherical region that was within the cancellous bone compartment were performed using image processing software provided with the micro-CT system (IPL V5.16, Scanco Medical AG). The parameters included the calculation of bone volume fraction (BV/TV), trabecular thickness (Tb.Th) trabecular number (Tb.N), trabecular spacing (Tb.Sp), structural model index (SMI), and degree of anisotropy (DA). Tb.Th, Tb.Sp, and Tb.N were determined based on direct measurement using a distance transformation method. The measured microstructural parameters were then assigned to the element located at the centroid of the sphere. Since the elements were around $1 \mathrm{~mm}$ in size, considerable overlap exists in the regions analyzed for neighboring elements.

For elements that were at least partly in the cortical compartment, a cortical bone volume fraction was defined as the volume of cortical bone within the element divided by the element volume that was within the cortical compartment as defined earlier. For elements that comprised both the cancellous and cortical compartments, the final BV/TV was based on a rule of mixtures for the cortical and cancellous bone parts, whereas the microstructural parameters were based on the cancellous bone only. Figure 1 depicts the mesh generation and bone microstructural analysis procedures.

In addition to the local volume fraction and microstructural measurements, the whole bone volume fraction was calculated from the micro-CT images as the total bone tissue volume divided by the total volume of the vertebra. Furthermore, the cancellous/cortical bone volume fraction was calculated as the total bone tissue volume divided by the total volume of the cancellous/cortical compartment.

\section{Finite element analyses}

In a next step, the meshed vertebrae created in the previous stages were used for FE analysis. Based on the element bone volume fraction measurements described earlier, isotropic material properties were defined for each element using the power-law relationship in Zysset-Curnier relationship while the fabric tensor was replaced by identity tensor [26]. Elasticplastic-damage constitutive behavior [27] was prescribed to simulate failure and post-failure behavior of the vertebrae under compression loading. This material model implements Hill's criterion as the yield criterion; it can account for plastic deformation and contains a damage variable $\mathrm{D}$ (range $0-1$, no to full damage) to account for the reduction of stiffness due to propagation of voids and cracks, and due to breakage of individual trabeculae. Nonlinear FE analyses were carried out using ANSYS (Ansys Inc., USA). The boundary conditions applied were chosen to mimic the experimental setting. Nodes at the inferior endplate were fixed in all directions, while a displacement in the axial direction was applied to nodes at superior endplate. A total compressive displacement of $3 \mathrm{~mm}$ was applied in 100 load increments, and for each step, the total reaction force was calculated. The force displacement curve peak was taken as the vertebral strength. 


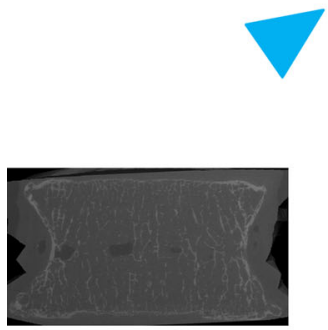

$\mu \mathrm{CT}$ images

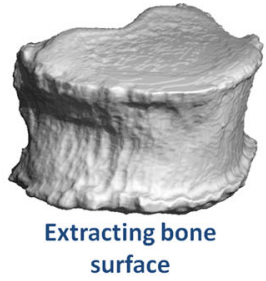

HOMOGENIZATION

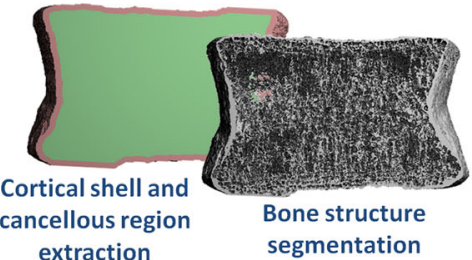

Fig. 1 Mesh morphing and bone microstructural analysis procedure
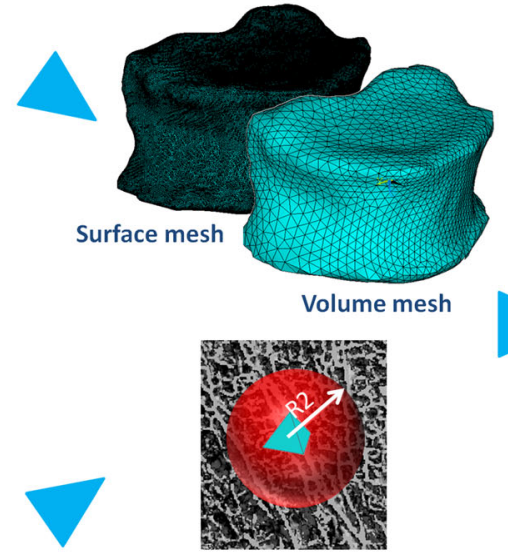

Measuring microStructural Parameters

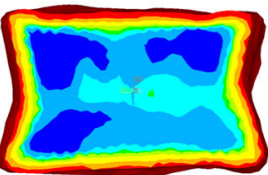

BV/TV

\section{Statistical analysis and visualization}

To investigate which parameter and which anatomical location best predicts bone strength, values for the bone volume fraction and microstructural parameters were collected for each element throughout the mesh template of 18 samples. This means for each element in the mesh template, 18 distinctive numbers per microstructural parameter were obtained. These 18 numbers then were correlated to the whole vertebral-body strength values of the 18 vertebrae as measured in the experiment to explore which element location and parameter correlated best to bone strength. Results were quantified by an adjusted element coefficient of determination $\left(\mathrm{R}^{2}\right)$ as well as the $p$ values. Using the mesh template as the geometry, contour plots of this element coefficient of determination enabled visualization of the regions that best correlate to the measured whole bone strength. Since with this procedure, we are, in fact, testing a new hypothesis for each element, a Bonferroni correction was used to adjust $p$ values. With a total of 51,119 elements (hypotheses), the required level of significance then becomes 1E-6. However, since all element properties are averaged over a 4-mm spherical region around the element, there is a lot of overlap in the analyzed region between neighboring elements. The actual number of non-overlapping samples is much less, and closer to 500, assuming a vertebral volume of around $32,000 \mathrm{~mm}^{3}$ and a sample of around $64 \mathrm{~mm}^{3}$. It can be argued that the Bonferroni correction as calculated above is too conservative and that it should correct for only 500 hypotheses, corresponding to a level of significance of 1E-4. In the present study, we therefore used both corrections. We visualized the $p$ values in contour plot and indicated in which regions significant correlation between element properties and whole vertebral strength were detected after applying both Bonferroni corrections.

In a first analysis, only BV/TV was considered as a predictor for bone strength. In a second analysis, a multiple regression analysis was performed that combined all measured parameters for a specific element to predict bone strength. Note that, since we were looking for a single best location, we did not aim at combining different parameters obtained from multiple locations.

To provide further insight in the average distribution of BV/ TV and its local variation, the average value of each element parameter (i.e., when averaged over the 18 specimens) was calculated as well as its coefficient of variation (CV).

To investigate if local values could better predict bone strength than whole bone volume fraction, the whole bone volume fraction and cancellous/cortical bone volume fraction of the 18 vertebrae were correlated to the whole bone strength values of the 18 vertebrae as well. Similarly, to investigate if local values could better predict bone strength than FEanalysis, the strength predicted from the non-linear FEanalyses was correlated to the whole bone strength values of the 18 vertebrae. Fisher $z$ transformation was used to test whether the correlations obtained for each method significantly differ from each other.

\section{Results}

The central regions of the vertebrae best predict the bone strength, with coefficients of determination in the range of 0.60 to 0.90 (Fig. 2). To better visualize the regions that best predict bone strength, the contour plots were thresholded such 
(a)

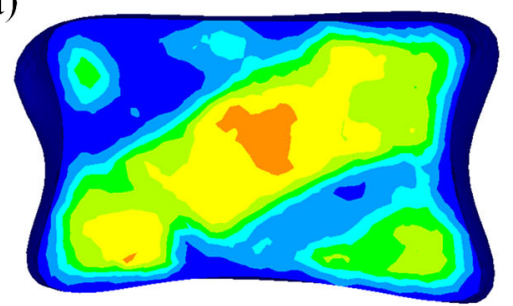

(b)

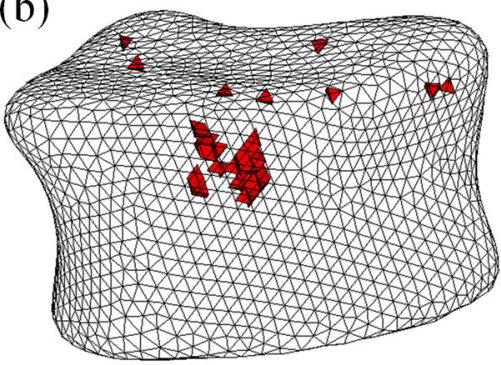

(d)

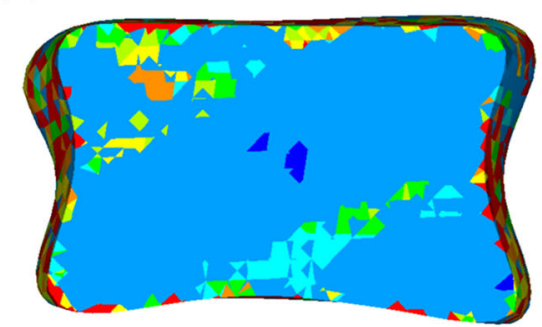

(f)

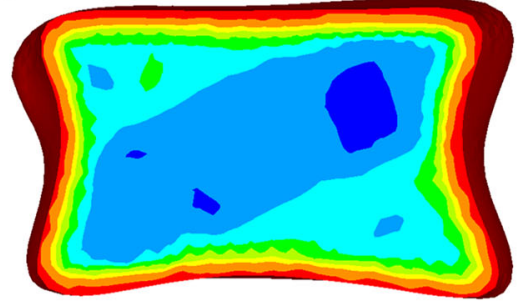

(g)

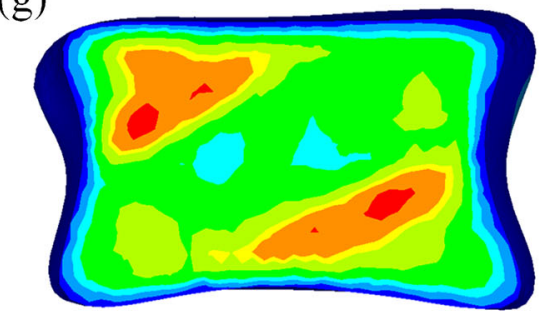

Fig. 2 a Contour plot of the coefficient of determination between whole vertebral-body strength and BV/TV, elements with R-squared value b above 0.75 and $\mathbf{c}$ above 0.90 , $\mathbf{d}$ contour plots of $p$ value distributions (element values) after Bonferroni correction for 51119 hypotheses or $\mathbf{e}$

that only elements with a coefficient of determination that exceeded 0.75 or 0.90 were shown (Fig. $2 b, c$ ). These plots confirmed that the central region is the best for predicting bone strength, and they also revealed that this location (element \#46205 in the mesh template, see supplemental data) explained $90 \%$ of the variation in whole vertebral-body

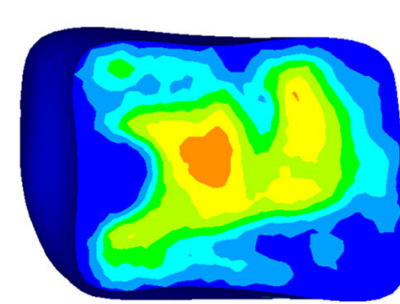

Coefficient of

Determination $\left(\mathrm{R}^{2}\right)$
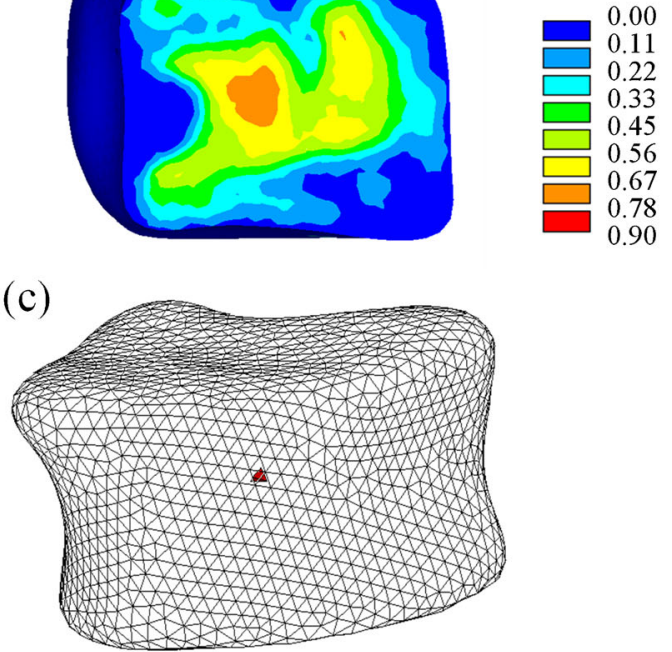

(e)

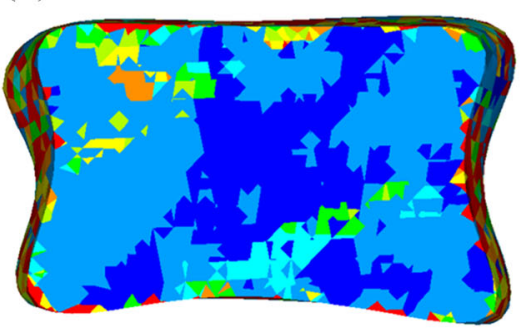

P-values
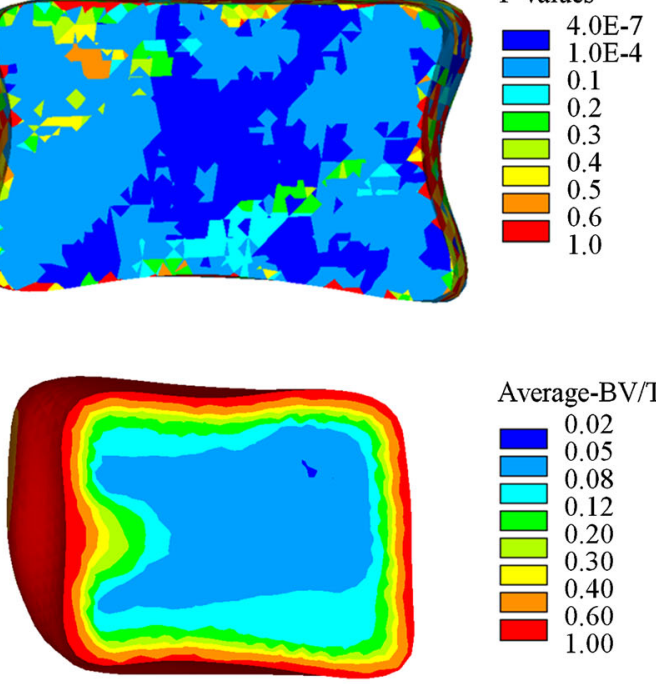

Average-BV/TV
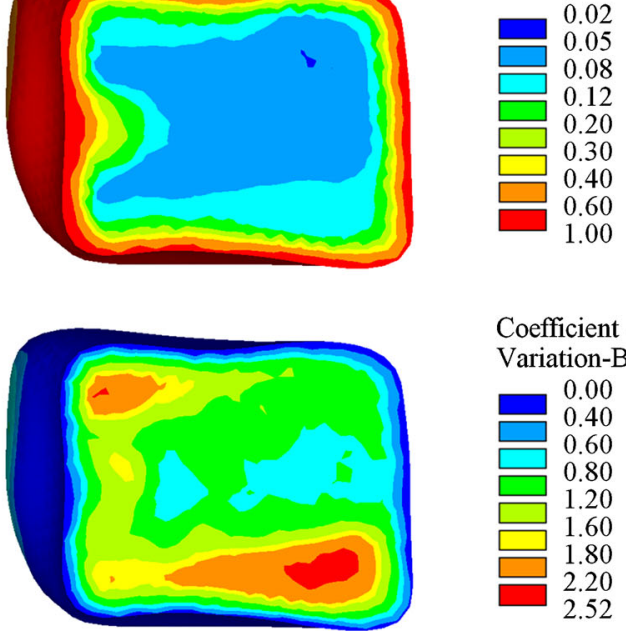

Coefficient of

Variation-BV/TV

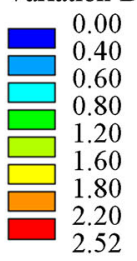

after correcting for 500 hypotheses, and $\mathbf{f}$ contour plots of average BV/ TV with $\mathbf{g}$ its $\mathrm{CV}$ within the population (left frontal section, right sagittal section)

strength (Fig. 5e). Significant correlations were found at the center of vertebra (dark blue regions on Fig. 2d-e). Figure 2f$\mathrm{g}$ depicts the average BV/TV and its coefficient of variation within the population. By combining these plots with Fig. 2a, it can be seen that the best predictive region is a region with a rather consistent low bone volume fraction. 
Fig. 3 Contour plots of coefficient of determination between whole vertebral strength and $\mathbf{a} \mathrm{Tb} . \mathrm{N}$ and $\mathbf{b} \alpha 1 \mathrm{BV} / \mathrm{TV}+$ $\alpha 2$ Tb.N (left frontal section, right sagittal section) (a)
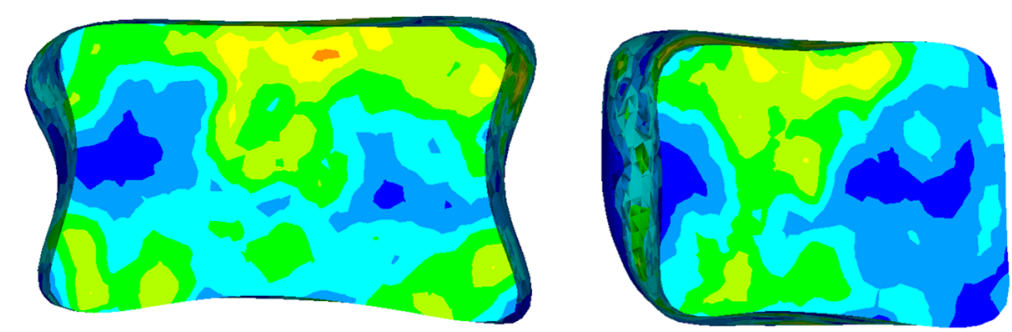

Coefficient of Determination $\left(\mathrm{R}^{2}\right)$

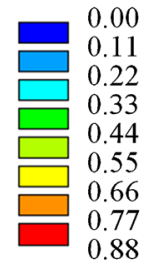

(b)

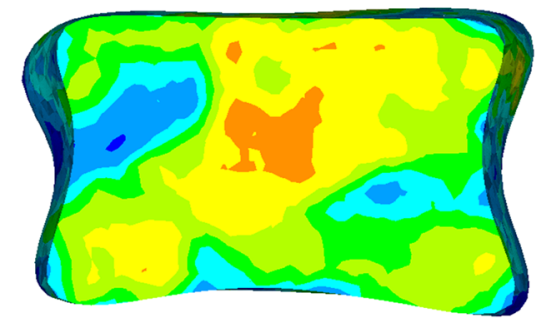

Coefficient of Determination $\left(\mathrm{R}^{2}\right)$

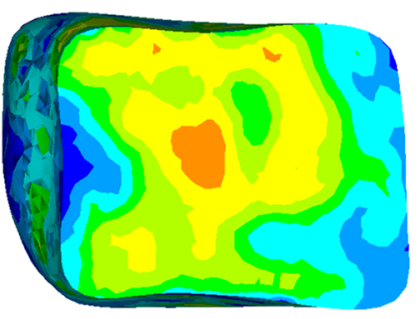

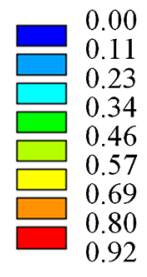

When analyzing the predictive value of the individual microstructural parameters, it was found that Tb.N better correlated with vertebral strength than other microstructural parameters (max $\mathrm{R}^{2}=0.88$ ). For this parameter, the regions that best predicted strength were found mainly near the endplates (Fig. 3a).

The other microstructural parameters, Tb.Th, Tb.Sp, SMI, and DA correlated much less with vertebral strength ( $\max \mathrm{R}^{2}$ $<0.83$ ). DA was the poorest predictor of the microstructural parameters analyzed $\left(\max \mathrm{R}^{2}<0.61\right)$.

Results of the multi-linear regression analysis revealed that combining BV/TV with microstructural parameters measured at that element can improve the prediction (Table 1). The combination of $\mathrm{BV} / \mathrm{TV}$ and $\mathrm{Tb} . \mathrm{N}$ could increase the coefficient of determination to $\mathrm{R}_{\mathrm{adj}}^{2}=0.91$. In this case also, the central regions best predict vertebral strength (Fig. 3b). The highest coefficient of determination $\mathrm{R}_{\mathrm{adj}}^{2}=0.97$ was obtained when taking all six microstructural parameters into account.

For the multi-linear regression model that combined all parameters, thresholding the coefficient of determination at $90 \%$ revealed a somewhat scattered plot of elements that exceeded that threshold, mainly in the central regions. When further increasing the threshold up to $98 \%$, one element located at the superior-posterior region (element \#18336 in the mesh template) remained. Measuring these six microstructural parameters at this particular location could explain over $98 \%$ of the variation in vertebral strength. (a)

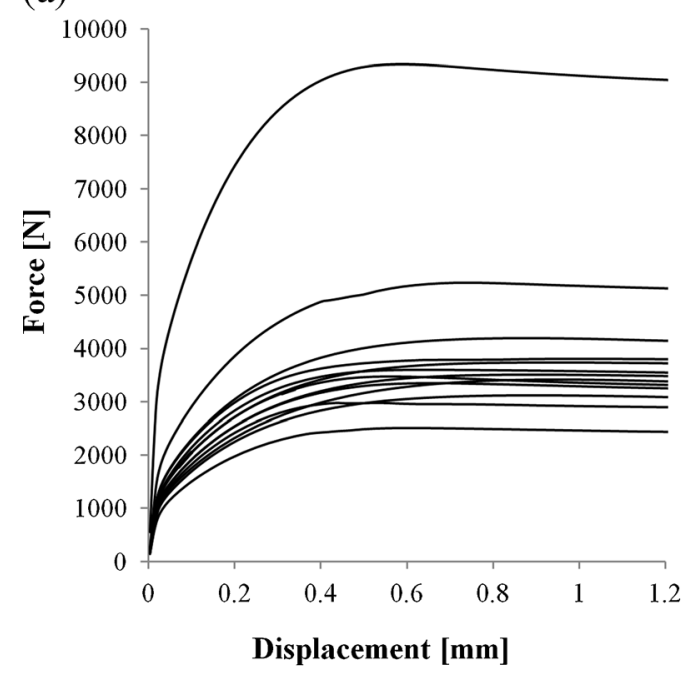

(b)
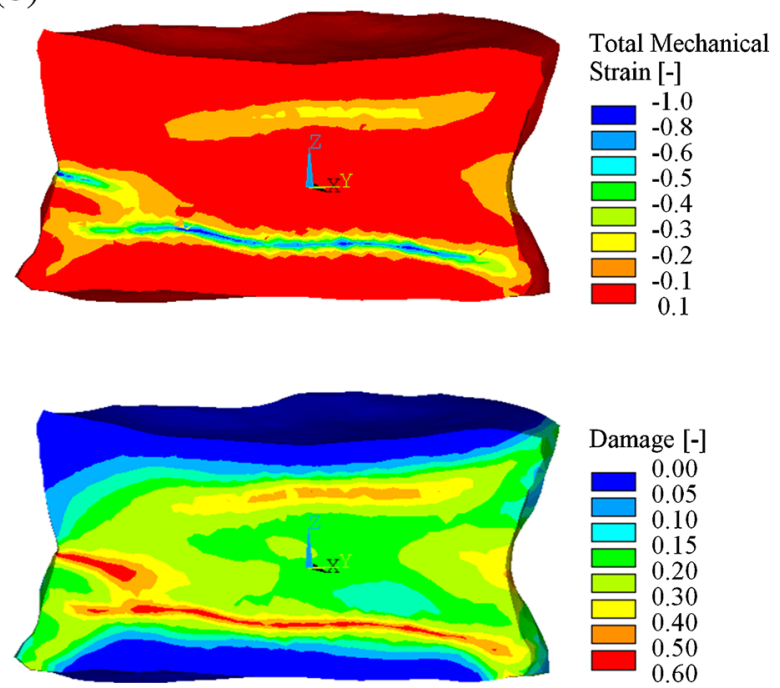

Fig. 4 a Force-displacement curves obtained from whole vertebral compression FE analyses $(n=18)$; $\mathbf{b}$ total mechanical strain and damage distribution in the vertebral body under compression test for a typical sample 
Table 1 Determination coefficient relating bone microstructural parameters and vertebral strength

* Refers to the location in the mesh template which is included as ESM

\begin{tabular}{|c|c|c|c|}
\hline $\begin{array}{l}\text { Bone microstructural } \\
\text { parameter }\end{array}$ & Location (element no.)* & $\begin{array}{l}\text { Max. adjusted determination } \\
\text { coefficient for measured } \\
\text { vertebral strength }\end{array}$ & $\begin{array}{l}\text { Mean and SD parameter } \\
\text { values for element with } \\
\text { max. R-squared value }\end{array}$ \\
\hline $\mathrm{BV} / \mathrm{TV}$ & 46205 & 0.89 & $0.0658 \pm 0.0498$ \\
\hline Tb.N & 21102 & 0.87 & $1.2498 \pm 0.3236$ \\
\hline Tb.Th & 6550 & 0.80 & $0.1311 \pm 0.0369$ \\
\hline Tb.Sp & 21102 & 0.75 & $0.8688 \pm 0.1777$ \\
\hline SMI & 48012 & 0.82 & $2.0575 \pm 0.9795$ \\
\hline DA & 4041 & 0.58 & $1.7377 \pm 0.4311$ \\
\hline$\alpha_{1} \mathrm{BV} / \mathrm{TV}+\alpha_{2} \mathrm{~Tb} . \mathrm{N}$ & 21102 & 0.91 & N/A \\
\hline $\begin{array}{l}\alpha_{1} \mathrm{BV} / \mathrm{TV}+\alpha_{2} \mathrm{~Tb} . \mathrm{N}+ \\
\alpha_{3} \mathrm{~Tb} . \mathrm{Th}\end{array}$ & 48274 & 0.90 & N/A \\
\hline $\begin{array}{c}\alpha_{1} \text { BV/TV }+\alpha_{2} \text { Tb.N }+ \\
\alpha_{3} \text { Tb.Th }+\alpha_{4} \text { Tb.Sp }\end{array}$ & 47073 & 0.92 & N/A \\
\hline $\begin{array}{l}\alpha_{1} \text { BV } / \mathrm{TV}+\alpha_{2} \text { Tb.N }+ \\
\alpha_{3} \text { Tb.Th }+\alpha_{4} \text { Tb.Sp }+ \\
\alpha_{5} \text { SMI }\end{array}$ & 9683 & 0.93 & N/A \\
\hline $\begin{array}{c}\alpha_{1} \text { BV } / \mathrm{TV}+\alpha_{2} \mathrm{~Tb} . \mathrm{N}+ \\
\alpha_{3} \mathrm{~Tb} . \mathrm{Th}+\alpha_{4} \mathrm{~Tb} . \mathrm{Sp}+ \\
\alpha_{5} \mathrm{SMI}+\alpha_{6} \mathrm{DA}\end{array}$ & 18336 & 0.97 & N/A \\
\hline
\end{tabular}

In contrast to the local measurement, whole bone, cancellous, and cortical bone volume fractions could explain only 64,68 , and $57 \%$ of the variation in measured bone strength, respectively. Figure $5 \mathrm{a}-\mathrm{c}$ depicts the correlation between these volume fractions and the vertebral strength values measured in the experiments.

Non-linear FE analyses of the vertebrae revealed typical failure behavior (Fig. 4). The simulated force displacement curves demonstrated that some of the samples show elasticperfectly plastic behavior at the apparent level, whereas for others, some softening occurs (Fig. 4a). Closer analysis of the results demonstrated the presence of bands in which the failure concentrates, in agreement with results described by others [27-29] (Fig. 4b). When correlating the FE-predicted and measured whole bone strengths, a coefficient of determination $\mathrm{R}^{2}=0.76$ was found (Fig. $5 \mathrm{~d}$ ).

Fisher $z$ transformation tests revealed that the correlation values for the local BV/TV-based prediction $\left(\mathrm{R}^{2}=0.90\right)$ and for the FE-based prediction $\left(\mathrm{R}^{2}=0.76\right)$ are not significantly different $(p=0.064)$. However, the correlation for the local $\mathrm{BV} / \mathrm{TV}$-based prediction was significantly better than that obtained for the whole bone BV/TV-based prediction $\left(\mathrm{R}^{2}=0.64 ; p=0.005\right)$.

\section{Discussion}

The results of this study demonstrate that accurate predictions of vertebral bone strengths can be made based on volume fraction and structural measurements at a specific anatomical location. Even when measuring local volume fraction only, predictions of whole bone strength were better than predictions based on whole bone density and at least as accurate as predictions from whole bone nonlinear FE analyses.

A key methodological innovation is the use of a combination of morphing and local microstructure measurement tools. We demonstrated that in this way, it is possible to measure volume fraction and microstructural parameters at welldefined anatomical positions within vertebrae. Since, after mesh morphing, each element is at a specific anatomical position, it becomes possible to specify the location by the element number. As long as the same mesh template is used, the same procedure can be applied to patient CT data, thus making it possible to perform local measurement in vivo with much lower acquisition time and radiation dose, and at the same anatomical locations as used in the present study.

The first goal of this study was to investigate at what anatomical location within the vertebrae local bone volume fraction best predicts whole bone strength. The coefficient of determination found $\left(\mathrm{R}^{2}=0.90\right)$ was surprisingly high and higher than the predictive value of whole bone volume fraction or values found by others [30-34]. The average bone volume fraction and the $\mathrm{CV}$ at this location (average $\mathrm{BV} / \mathrm{TV}=$ 0.07 and $C V=0.80$ ) were in the midrange, suggesting that this is not a very weak spot or a spot at which bone volume fraction undergoes drastic changes that would correlate with bone strength. Results of the FE analysis revealed that also the stresses and strains during compression were in the midrange of values found throughout the vertebra while the model did not predict fracture for this element in most cases. This is in agreement with results of micro-FE analyses recently presented by others which also suggest that failure does not accumulate at the vertebral center but rather near the endplates [35]. 
Fig. 5 Vertebra strength predictions with a whole bone volume fraction, $\mathbf{b}$ cancellous bone volume fraction, $\mathbf{c}$ cortical bone volume fraction, and $\mathbf{d}$ nonlinear FE analyses; $\mathbf{e}$ regression plot of the $\mathrm{BV} / \mathrm{TV}$ values measured at element \#46205 and whole bone strength values (excluding the sample with highest strength value reduces the R-squared value to $83 \%$ ) (a)

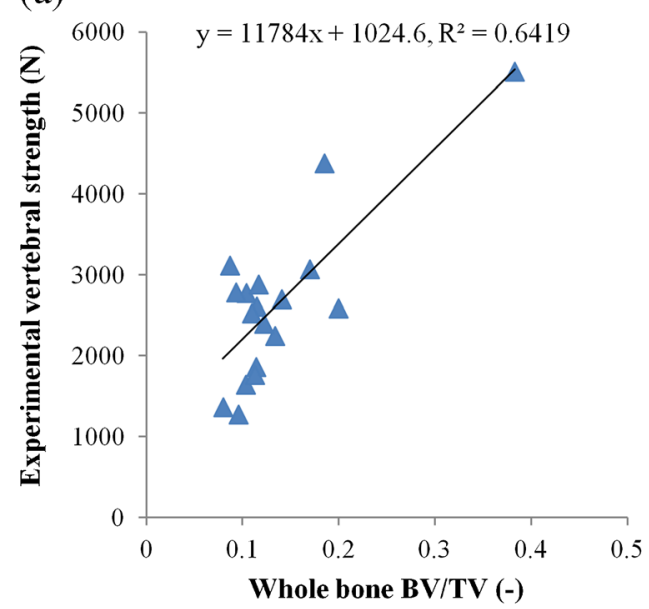

(b)

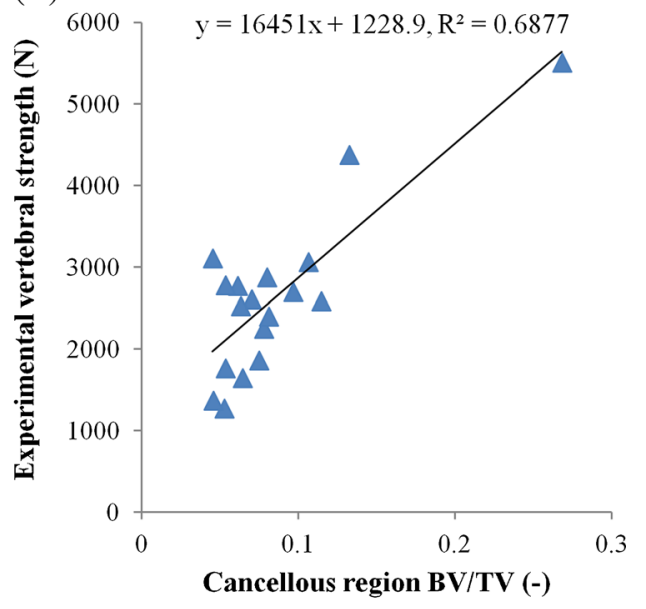

(d)

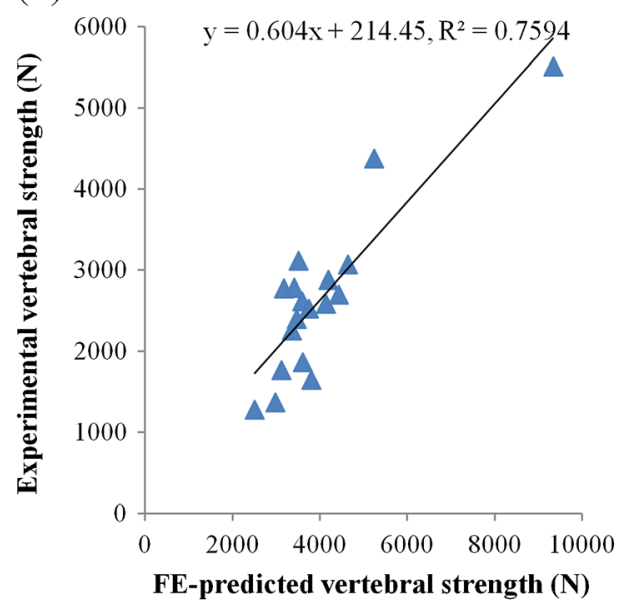

(e)

(c)
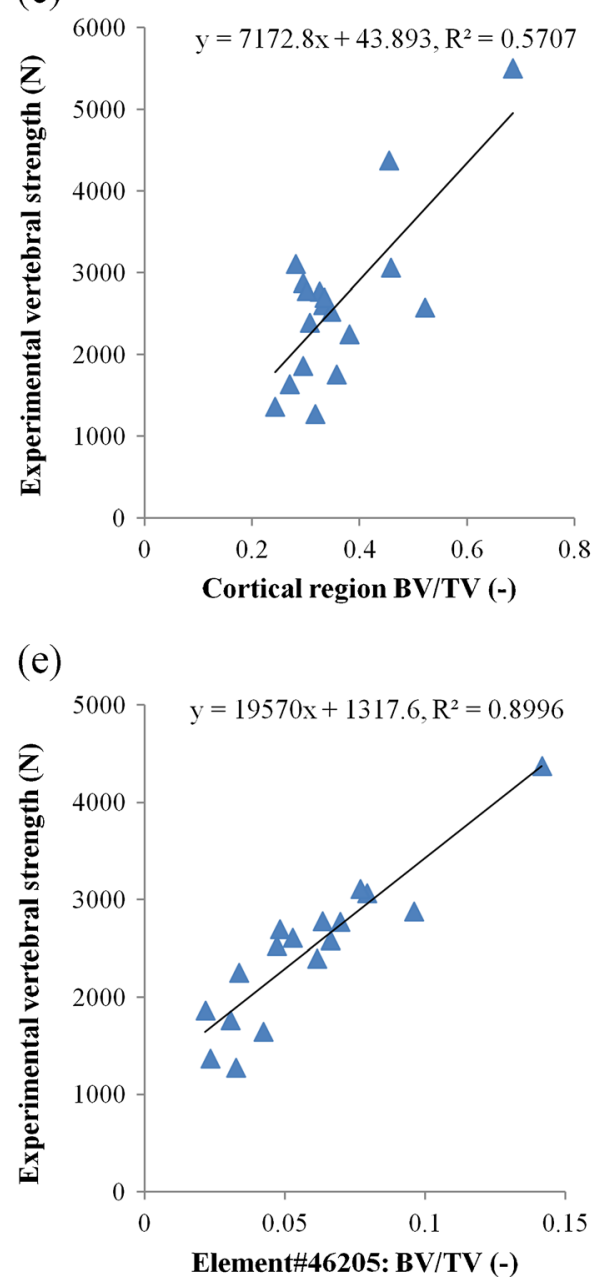

Taken together, these results indicate that the particular location at the center of vertebra may be a good predictor mainly because of the consistent correlation between BV/TV and bone strength, and not because it is the weakest link during loading.
A second goal was to investigate if the prediction can be further improved by measuring microstructural parameters. As expected, adding more parameters improved the prediction. Adding more parameters, however, also resulted in the selection of different anatomical regions. For instance, adding 
Tb.N, Tb.Th, and Tb.Sp to BV/TV in multi-linear regression analysis results in a high determination coefficient within elements far from the vertebra central region. Interestingly, these selected elements are mostly scattered at locations where the FE-model predicts high damage to occur. This suggests that adding more microstructural parameters to the regression analysis leads to the identification of the weakest links, while $\mathrm{BV} / \mathrm{TV}$ alone is not sensitive enough to do so and thus identifies a region where bone density varies most consistently with bone strength.

A third goal was to investigate if this approach could better predict bone strength than whole bone volume fraction and non-linear whole bone finite element analysis with volume fraction-dependent local stiffness and strength assignment. Our results demonstrate that this is the case. Whole bone volume fraction and cancellous bone volume fraction could predict only 64 and $68 \%$ of the variation in bone strength, respectively, whereas local volume fraction could explain over $90 \%$. Strength obtained from FE analyses predicted $76 \%$ of the variation in bone strength, which also is less than the local measures. The correlation between FE and experimental results found here is in accordance with previous studies [28, 36-40]; Dall'Ara et al. (2010) found a determination coefficient of 0.79 between FE-predicted vertebral strength and experimental values. It should be emphasized that the locations that we identified as the best predictor for vertebral strength represent the microstructure of the bone in a 4-mm spherical region around the element centroid. It is not possible to make these regions smaller, since that would violate the continuum assumption necessary to calculate meaningful bone volume fraction and microstructural parameters [25]. Increasing the size of the sphere would be possible, but would obviously lead to a reduction of the effective resolution of the anatomical location determination. To investigate if the results are dependent on the size of the sphere, we did some sensitivity analyses in which we varied the sphere radius from 4 to $8 \mathrm{~mm}$. It was found that the actual chosen size has a very small effect on the calculated bone volume fraction and other microstructural parameters.

As mentioned earlier, the coefficient of determination found when correlating the local density at the vertebral center and vertebral strength $\left(\mathrm{R}^{2}=0.90\right)$ was surprisingly high. In general, when searching correlations between many thousands of input parameters and one output parameter (i.e., testing many hypotheses at the same time), it is possible that unrealistic high correlations are detected. Even after applying a very conservative Bonferroni correction to adjust the level of significance, significant correlations were found for parameters measured at the central region. To further investigate if the high correlations found are realistic, we did a few additional analyses. First, we recalculated all the results, but used random values for bone strength. In these analyses, the coefficient of determination value found was less than 0.49 . Noteworthy was that the distribution of the coefficient of determination throughout the vertebral body, in this case was very low at the center whereas slightly higher values were found near the cortical boundaries (Fig. 6). This can be explained by the fact that in the cortical region, values do not vary much between subjects. These "constant" regions are then the best predictors of random strength values. When using a significance level of 1E-4, a few cortical elements were still identified as having their BV/TV significantly correlated to the random strength value, but when using a significance level of 1E-6, none of the correlations was found to be statistically significant. In contrast, when using real bone strength values, cluster of high predictive regions were found at the center of vertebra (Fig. 2a, b) and the coefficient of determination near the cortical boundaries was very low. Second, we subdivided the
Fig. 6 a Contour plot of coefficient of determination between randomly assigned whole vertebral-body strength values and measured $\mathrm{BV} / \mathrm{TV}$ values, $\mathbf{b} p$ values (a)
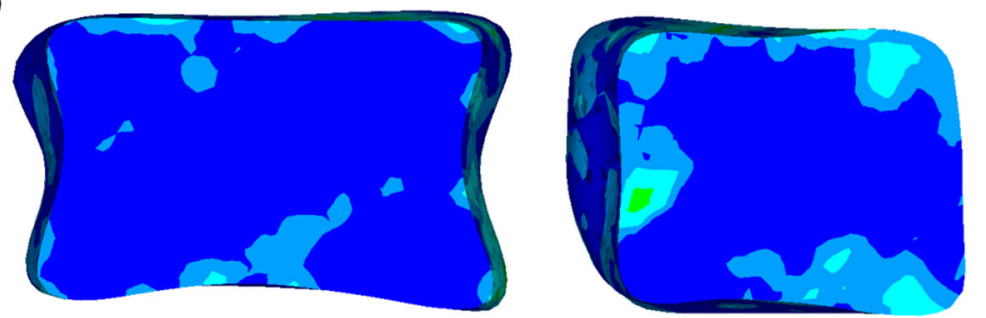

Coefficient of Determination $\left(\mathrm{R}^{2}\right)$

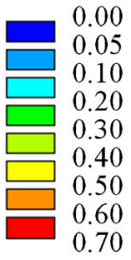

(b)

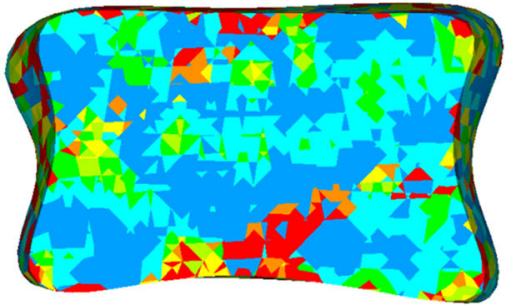

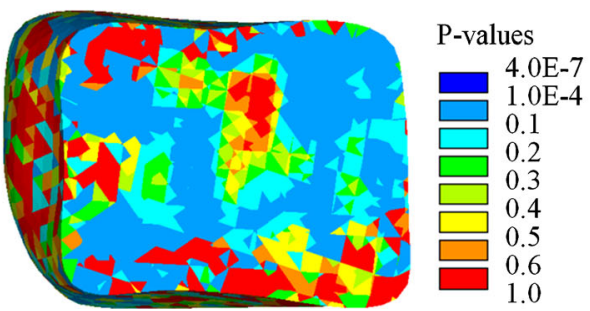


group of 18 vertebrae used in this study into two groups of 10 and 8 vertebrae. The group of ten vertebrae was used to find the best predictive region (element) in the same way as done earlier for the full dataset. The coefficient of determination when correlating local density and vertebral strength for these ten vertebrae $\left(\mathrm{R}^{2}=0.97\right)$ was even higher than for the full dataset, but the best predicting element (\#46401) was very close to the one found earlier. The regression constants obtained from this analysis then was used to predict the strength of the other eight vertebrae. In this case, the coefficient of determination was less $\left(\mathrm{R}^{2}=0.77\right)$ and almost the same as that found for the FE-predictions.

Although we did not explicitly investigate the sensitivity of the approach used here for errors in the mesh morphing procedure, this error was addressed implicitly. Since the mesh morphing tool was used 18 times, for all vertebrae used in this study, large deviations from the intended anatomical position would lead to variance in the parameters obtained at that position that is unrelated to bone strength. If that variance is high, the location, thus, will likely not be a suitable predictor for bone strength. Conversely, it is possible that locations that are good predictors for bone strength are locations that are relatively insensitive to such errors in the positioning. This could explain the fact that the locations that best predict the failure load of the vertebrae was not the same as the highest loaded region found in the FE-models.

There are several limitations of this study; first, only 18 vertebrae were included in the present study. However, the donors from which these vertebrae were obtained are representative for elderly at risk of vertebral fracture. Second, we used micro-CT images to measure bone microstructural parameters in this study. From standard clinical CT scans, however, only bone density measurements can be made. Since high correlations exist between BV/TV and bone density as measured with QCT [41, 42], we expect that the results can be reasonably translated to a clinical setting using QCT, although obviously the predictive value will be limited to that of BV/ $\mathrm{TV}$, which, however, still explained $90 \%$ of the variation in strength. It is worth mentioning also that recent studies using high-resolution flat panel CT systems have demonstrated that at least some microstructural parameters can be measured in vivo [11, 43-46]. In particular, these studies demonstrated that $\mathrm{Tb} . \mathrm{N}$ can be measured rather adequate in vivo. Interestingly, the combination of BV/TV and Tb.N was found to be one of the combinations that could considerably improve the prediction of vertebral strength, indicating that this could be a promising parameter to include.

Third, our FE-model modeled bone as an isotropic material, even though the material model used could account for anisotropy by measuring a fabric tensor [47]. We have chosen not to do so here to make the FE-results comparable with the nowadays clinical practice and to make sure that the FE-model contains the same information as the regression model based on volume fraction only. It is well possible though that including anisotropy could enhance the predictions of the FEanalysis $[48,49]$.

Fourth, the specimens were stored in formalin before testing. It has been shown that this can affect the mechanical properties of the bone [50, 51]. As with the previous comment, we here assume that this error would be consistent for all vertebrae and thus not affect the correlation too much.

In conclusion, the results suggest that the local density measurement technique investigated here may better predict whole vertebral-body strength than current methods measuring whole bone density. Although the dataset used here was small and should be replicated in a larger sample, the fact that it can be translated to a clinical setting renders it an interesting novel approach for patient-specific strength prediction. Clinical studies with a broader population, however, will need to confirm whether these techniques may permit better prediction of vertebral fracture risk than currently possible DXA-, QCT-, or FE-derived measures.

Acknowledgments Funding from the European Union for the osteoporotic virtual physiological human project (VPHOP FP7-ICT2008223865 ) is gratefully acknowledged.

Conflicts of interest Bert van Rietbergen is a consultant for Scanco Medical AG.

\section{References}

1. Riggs BL, Melton Iii LJ (1995) The worldwide problem of osteoporosis: insights afforded by epidemiology. Bone 17:S505-S511

2. Grigoryan M, Guermazi A, Roemer F, Delmas P, Genant H (2003) Recognizing and reporting osteoporotic vertebral fractures. Eur Spine J 12:S104-S112

3. Legrand E, Chappard D, Pascaretti C, Duquenne M, Krebs S, Rohmer V, Basle M-F, Audran M (2000) Trabecular bone microarchitecture, bone mineral density, and vertebral fractures in male osteoporosis. J Bone Miner Res 15:13-19

4. Bultink IEM, Lems WF, Kostense PJ, Dijkmans BAC, Voskuyl AE (2005) Prevalence of and risk factors for low bone mineral density and vertebral fractures in patients with systemic lupus erythematosus. Arthritis Rheum 52:2044-2050

5. Bolotin HH (2007) DXA in vivo BMD methodology: an erroneous and misleading research and clinical gauge of bone mineral status, bone fragility, and bone remodeling. Bone 41:138-154

6. Kanis J, Borgstrom F, Laet C, Johansson H, Johnell O, Jonsson B, Oden A, Zethraeus N, Pfleger B, Khaltaev N (2005) Assessment of fracture risk. Osteoporos Int 16:581-589

7. Siris ES, Chen Y, Abbot TA et al (2004) Bone mineral density thresholds for pharmacological intervention to prevent fractures. Arch Intern Med 164:1108-1112

8. Lochmüller E-M, Müller R, Kuhn V, Lill CA, Eckstein F (2003) Can novel clinical densitometric techniques replace or improve DXA in predicting bone strength in osteoporosis at the hip and other skeletal sites? J Bone Miner Res 18:906-912

9. Perilli E, Briggs AM, Kantor S, Codrington J, Wark JD, Parkinson IH, Fazzalari NL (2012) Failure strength of human vertebrae: 
prediction using bone mineral density measured by DXA and bone volume by micro-CT. Bone 50:1416-1425

10. Briggs A, Perilli E, Parkinson I, Kantor S, Wrigley T, Fazzalari N, Wark J (2012) Measurement of subregional vertebral bone mineral density in vitro using lateral projection dual-energy X-ray absorptiometry: validation with peripheral quantitative computed tomography. J Bone Miner Metab 30:222-231

11. Mulder L, van Rietbergen B, Noordhoek NJ, Ito K (2012) Determination of vertebral and femoral trabecular morphology and stiffness using a flat-panel C-arm-based CT approach. Bone 50:200 208

12. Duan Y, Parfitt AM, Seeman E (1999) Vertebral bone mass, size, and volumetric density in women with spinal fractures. J Bone Miner Res 14:1796-1802

13. Seeman E, Duan Y, Fong C, Edmonds J (2001) Fracture Site-Specific Deficits in Bone Size and Volumetric Density in Men with Spine or Hip Fractures. J Bone Miner Res 16:120-127

14. Yoganandan N, Pintar FA, Stemper BD, Baisden JL, Aktay R, Shender BS, Paskoff G, Laud P (2006) Trabecular bone density of male human cervical and lumbar vertebrae. Bone 39:336-344

15. Lang TF, Li J, Harris ST, Genant HK (1999) Assessment of vertebral bone mineral density using volumetric quantitative CT. J Comput Assist Tomogr 23

16. Tabensky AD, Deluca V, Briganti E, Seeman E, Williams J (1996) Bone mass, areal, and volumetric bone density are equally accurate, sensitive, and specific surrogates of the breaking strength of the vertebral body: an in vitro study. J Bone Miner Res 11:1981-1988

17. Lochmüller EM, Bürklein D, Kuhn V, Glaser C, Müller R, Glüer CC, Eckstein F (2002) Mechanical strength of the thoracolumbar spine in the elderly: prediction from in situ dual-energy X-ray absorptiometry, quantitative computed tomography (QCT), upper and lower limb peripheral QCT, and quantitative ultrasound. Bone 31:77-84

18. Banse X, Devogelaer JP, Munting E, Delloye C, Cornu O, Grynpas M (2001) Inhomogeneity of human vertebral cancellous bone: systematic density and structure patterns inside the vertebral body. Bone 28:563-571

19. Stauber M, Müller R (2006) Age-related changes in trabecular bone microstructures: global and local morphometry. Osteoporos Int 17: 616-626

20. Parkinson IH, Badiei A, Stauber M, Codrington J, Müller R, Fazzalari NL (2012) Vertebral body bone strength: the contribution of individual trabecular element morphology. Osteoporos Int 23 : 1957-1965

21. Gong H, Zhang M, Qin L, Lee KKH, Guo X, Shi SQ (2006) Regional variations in microstructural properties of vertebral trabeculae with structural groups. Spine 31:24-32

22. Briggs AM, Perilli E, Parkinson IH, Wrigley TV, Fazzalari NL, Kantor S, Wark JD (2010) Novel assessment of subregional bone mineral density using DXA and pQCT and subregional microarchitecture using micro-CT in whole human vertebrae: applications, methods, and correspondence between technologies. J Clin Densitom 13:161-174

23. Lochmüller EM, Pöschl K, Würstlin L, Matsuura M, Müller R, Link TM, Eckstein F (2008) Does thoracic or lumbar spine bone architecture predict vertebral failure strength more accurately than density? Osteoporos Int 19:537-545

24. Grassi L, Hraiech N, Schileo E, Ansaloni M, Rochette M, Viceconti M (2011) Evaluation of the generality and accuracy of a new mesh morphing procedure for the human femur. Med Eng Phys 33:112120

25. Harrigan TP, Jasty M, Mann RW, Harris WH (1988) Limitations of the continuum assumption in cancellous bone. J Biomech 21:269-275

26. Zysset PK, Curnier A (1995) An alternative model for anisotropic elasticity based on fabric tensors. Mech Mater 21:243-250

27. Charlebois M, Jirasek M, Zysset PK (2010) A nonlocal constitutive model for trabecular bone softening in compression. Biomech Model Mechanobiol 9:597-611
28. Imai K, Ohnishi I, Bessho M, Nakamura K (2006) Nonlinear finite element model predicts vertebral bone strength and fracture site. Spine 31

29. Kopperdahl DL, Roberts AD, Keaveny TM (1999) Localized damage in vertebral bone is most detrimental in regions of high strain energy density. J Biomech Eng 121:622-628

30. Moro M, Hecker AT, Bouxsein ML, Myers ER (1995) Failure load of thoracic vertebrae correlates with lumbar bone mineral density measured by DXA. Calcif Tissue Int 56:206-209

31. Hulme PA, Boyd SK, Ferguson SJ (2007) Regional variation in vertebral bone morphology and its contribution to vertebral fracture strength. Bone 41:946-957

32. Edmondston SJ, Singer KP, Day RE, Breidahl PD, Price RI (1994) In vitro relationships between vertebral body density, size, and compressive strength the elderly thoracolumbar spine. Clin Biomech 9: $180-186$

33. Cheng XG, Nicholson PHF, Boonen S, Lowet G, Brys P, Aerssens J, van der Perre G, Dequeker J (1997) Prediction of vertebral strength in vitro by spinal bone densitometry and calcaneal ultrasound. J Bone Miner Res 12:1721-1728

34. Ebbesen EN, Thomsen JS, Beck-Nielsen H, Nepper-Rasmussen HJ, Mosekilde L (1999) Lumbar vertebral body compressive strength evaluated by dual-energy X-ray absorptiometry, quantitative computed tomography, and ashing. Bone 25:713-724

35. Fields AJ, Nawathe S, Eswaran SK, Jekir MG, Adams MF, Papadopoulos P, Keaveny TM (2012) Vertebral fragility and structural redundancy. J Bone Miner Res 27:2152-2158

36. Dall'Ara E, Schmidt R, Pahr D, Varga P, Chevalier Y, Patsch J, Kainberger F, Zysset P (2010) A nonlinear finite element model validation study based on a novel experimental technique for inducing anterior wedge-shape fractures in human vertebral bodies in vitro. $\mathrm{J}$ Biomech 43:2374-2380

37. Matsumoto T, Ohnishi I, Bessho M, Imai K, Ohashi S, Nakamura K (2009) Prediction of vertebral strength under loading conditions occurring in activities of daily living using a computed tomography-based nonlinear finite element method. Spine 34

38. Buckley JM, Loo K, Motherway J (2007) Comparison of quantitative computed tomography-based measures in predicting vertebral compressive strength. Bone 40:767-774

39. Crawford RP, Cann CE, Keaveny TM (2003) Finite element models predict in vitro vertebral body compressive strength better than quantitative computed tomography. Bone 33:744-750

40. Mirzaei M, Zeinali A, Razmjoo A, Nazemi M (2009) On prediction of the strength levels and failure patterns of human vertebrae using quantitative computed tomography (QCT)-based finite element method. J Biomech 42:1584-1591

41. Dall'Ara E, Varga P, Pahr D, Zysset P (2011) A calibration methodology of QCT BMD for human vertebral body with registered microCT images. Med Phys 38:2602-2608

42. Schmidt C, Priemel M, Kohler T, Weusten A, Müller R, Amling M, Eckstein F (2003) Precision and accuracy of peripheral quantitative computed tomography (pQCT) in the mouse skeleton compared with histology and microcomputed tomography $(\mu \mathrm{CT})$. J Bone Miner Res 18:1486-1496

43. Bredella MA, Misra M, Miller KK, Madisch I, Sarwar A, Cheung A, Klibanski A, Gupta R (2008) Distal radius in adolescent girls with anorexia nervosa: trabecular structure analysis with high-resolution flat-panel volume CT1. Radiology 249:938-946

44. Walsh CJ, Phan CM, Misra M, Bredella MA, Miller KK, Fazeli PK, Bayraktar HH, Klibanski A, Gupta R (2010) Women with anorexia nervosa: finite element and trabecular structure analysis by using flatpanel volume CT. Radiology 257:167-174

45. Cheung A, Bredella M, Al Khalaf MM, Grasruck M, Leidecker C, Gupta R (2009) Reproducibility of trabecular structure analysis using flat-panel volume computed tomography. Skeletal Radiol 38:10031008 
46. Gupta R, Grasruck M, Suess C, Bartling S, Schmidt B, Stierstorfer K, Popescu S, Brady T, Flohr T (2006) Ultra-high resolution flat-panel volume CT: fundamental principles, design architecture, and system characterization. Eur Radiol 16:1191-1205

47. Hazrati Marangalou J, Ito K, van Rietbergen B (2012) A new approach to determine the accuracy of morphology-elasticity relationships in continuum FE analyses of human proximal femur. J Biomech 45:2884-2892

48. Pahr DH, Zysset PK (2009) A comparison of enhanced continuum FE with micro FE models of human vertebral bodies. J Biomech 42: $455-462$
49. Hazrati Marangalou J, Ito K, Cataldi M, Taddei F, van Rietbergen B (2013) A novel approach to estimate trabecular bone anisotropy using a database approach. J Biomech 46:23562362

50. Edmondston SJ, Singer KP, Day RE, Breidahl PD, Price RI (1994) Formalin fixation effects on vertebral bone density and failure mechanics: an in vitro study of human and sheep vertebrae. Clin Biomech 9:175-179

51. Wilke H-J, Krischak S, Claes LE (1996) Formalin fixation strongly influences biomechanical properties of the spine. J Biomech 29: $1629-1631$ 